\title{
Upper Normal Limit of Thyroid-Stimulating Hormone and Metabolic Syndrome in Iranian Patients with Obesity
}

\author{
Zohreh Nozarian' $^{1}$, Alireza abdollahi ${ }^{1}$, Vahid Mehrtash' ${ }^{2}$, Hirbod Nasiri Bonaki ${ }^{2}$ \\ 1. Dept. of Pathology, Imam Hospital Complex, Tehran University of Medical Sciences, Tehran, Iran. \\ 2. School of Medicine, Tehran University of Medical Sciences, Tehran, Iran.
}

\begin{tabular}{l} 
KEYWORDS \\
\hline Metabolic Syndrome \\
Thyroid-Stimulating Hormone \\
Obesity, Euthyroid \\
\hline
\end{tabular}

Article Info

Received 12 Oct 2015;

Accepted 11 Apr 2016;

Published Online 30 Aug 2016;
ABSTRACT

Background: The current study aimed at evaluating the association between thyroid-stimulating hormone (TSH) level in upper normal limits with metabolic syndrome, modifiable risk factor for cardiovascular disease, and its components according to Adult Treatment Panel III of National Cholesterol Education Program.

Methods: The current cross sectional study recruited 82 patients with euthyroid overweight or obesity. They all had body mass index (BMI) higher than $25 \mathrm{~kg} / \mathrm{m}^{2}$. The patients were categorized in 2 groups: Group 1 (patients with metabolic syndrome) and Group 2 (patients with non-metabolic syndrome). Demographic features and anthropometric indices were all appraised by a trained examiner. Metabolic syndrome components, BMI, age, gender, C-reactive protein (CRP), and thyroid function test (TFT) were assessed and compared.

Results: Age, triglyceride level, waist circumference, hypertension frequency, BMI and CRP were significantly higher in group 1. The most prevalent metabolic syndrome criterion was low level of serum high density lipoprotein (HDL). Patients with metabolic syndrome had greater TSH level, but it was not statistically significant (P-value=0.636). Euthyroid patients with TSH levels in the range of 3.88$5 \mathrm{mIU} / \mathrm{L}$ had 5.89 (95\% confidence interval $(\mathrm{CI})=1.02$ to 17.64$)$ times higher risk of developing metabolic syndrome than other TSH values. After age adjustment, the relationship between the upper quartile of TSH level and the metabolic syndrome became insignificant $(\mathrm{OR}=2.97,95 \% \mathrm{CI}=0.51$ to 17.2$)$.

Conclusion: TSH in upper normal limits was statistically correlated with metabolic syndrome. However, after adjustment for age, it became insignificant. Relationship between thyroid hormones and metabolic syndrome may be confounded by other important cardiovascular risk factors in euthyroid patients.

Corresponding Information: Dr Alireza Abdollahi; Dept of Pathology, Imam Hospital Complex, Tehran University of Medical Sciences, Tehran, Iran. Tel: +989121220588. Email: dr_p_abdollahi@yahoo.com.

Copyright $\odot$ 2017, IRANIAN JOURNAL OF PATHOLOGY. This is an open-access article distributed under the terms of the Creative Commons Attribution-noncommercial 4.0 International License which permits copy and redistribute the material just in noncommercial usages, provided the original work is properly cited.

\section{Introduction}

Many modifiable cardiovascular disease (CVD) risk factors are under the umbrella of metabolic syndrome (MetS) definition. Hypertension (HTN), dyslipidemia (DLP), insulin resistance, and abdominal obesity are considered as traditional CVD risk factors and MetS traits. The first National Cholesterol Education Program- Adult Treatment Panel (ATP III) guidelines were developed in 2001 and updated in 2005. It explicitly focused on cardiovascular hazards of different MetS traits, containing the following criteria: Abdominal obesity, defined as a waist circumference (WC) $>102 \mathrm{~cm}$ in males and $>88 \mathrm{~cm}$ in females, serum triglycerides (TG) $\geq 150 \mathrm{mg} / \mathrm{dL}$ or normal values under treatment, serum high density lipoprotein cholesterol (HDL-C) $<40 \mathrm{mg} / \mathrm{dL}$ in males and $<50$ $\mathrm{mg} / \mathrm{dL}$ in females or normal values under treatment, blood pressure (BP) $>130 / 85 \mathrm{mmHg}$ or controlled BP under antihypertensive treatment, fasting blood sugar (FBS) $\geq 100 \mathrm{mg} / \mathrm{dL}$ or drug treatment for the 
elevated blood glucose (1). The high prevalence of MetS in the developed countries, $25 \%$ in recent reports, and its adverse contribution to atherosclerosis development (2) has made it an important public health issue.

The prevalence of obesity and its related comorbidities is surprisingly increasing and is considered a global epidemic. The probability of lifetime overweight and obesity is $50 \%$ and $25 \%$ in the United States, respectively (3). Abdominal obesity, a big concern in patients with MetS, is discussed in the literature as a marker of CVD incidence (4). WC is the representative of abdominal obesity in ATPIII definition for MetS.

The pathophysiological effect of thyroid function on lipid and glucose metabolisms, blood pressure, and CVD were reported (5) and subclinical hypothyroidism was associated with MetS in previous studies $(6,7)$. Indeed, the relation between thyroid stimulating hormone (TSH) and MetS components is investigated. Most cardiovascular events occur in euthyroid patients (5); hence, the study of association between TSH levels and cardiovascular risk factors and MetS traits is still on the table. In recent studies, the positive relationship between high amounts of TSH level within normal range (upper normal limits) and CVD risk factors are shown $(8,9)$.

High-sensitivity C-reactive protein (hs-CRP) as a cardinal marker of systemic inflammation seems to be related to atherosclerosis and CVD (10). In a previous study in the Japanese population, hs-CRP was suggested as another criterion for MetS (11).

The present study aimed to evaluate the relationship between TSH levels within normal range and MetS and its components in euthyroid patients with body mass index $(\mathrm{BMI})>25 \mathrm{~kg} / \mathrm{m}^{2}$.

\section{Materials and Methods}

The current cross sectional study selected 82 patients with overweight and obesity from the day clinic of Imam Khomeini Hospital Complex from June to August 2015. They were all struggling with obesity complications and willing to take a stable diet. Basic and demographic features were recorded according to the researcher made questionnaire. A trained examiner evaluated the patients' blood pressure $(\mathrm{mmHg})$, weight $(\mathrm{kg})$, height (meter) and WC $(\mathrm{cm})$. Weight with a light clothing and height without shoes were measured and BMI was calculated as weight divided by height squared $\left(\mathrm{kg} / \mathrm{m}^{2}\right)$. Non-stretchable tape around the waist at the level of the iliac crest and at the end of normal expiration was used to define WC. Blood samples were obtained after an overnight fast of at least 10 hours. Laboratory tests included lipid profile (total cholesterol (TC), HDL, low density lipoprotein (LDL) and TG), FBS, and hs-CRP.

The blood samples were stored at $-80^{\circ} \mathrm{C}$ at the Imam Khomeini Hospital Complex laboratory to measure thyroid function test (TFT). In the current study, normal ranges for TFT were as follows: $0.5<$ $\mathrm{TSH}<5(\mathrm{mIU} / \mathrm{L}), 4.5<$ total T4 $<11.5(\mathrm{ng} / \mathrm{dL})$ and $75<$ total $\mathrm{T} 3<200(\mathrm{ng} / \mathrm{dL})$, using the automated immune chemiluminescent assay (ICMA) kits (Abbott, IL, USA). Cut off values and MetS criteria were according to ATP III MetS definition. Patients with 3 or more traits were considered to have MetS. The study protocol was approved by the Ethics Committee of Tehran University of Medical Sciences. Furthermore, informed consent was taken from patients before evaluating their profile.

\section{Statistical Analysis:}

The data were analyzed by SPSS software version 14 (SPSS Inc., Chicago, IL, USA). Categorical variables were reported as frequencies and compared by Pearson Chi-square test. Continuous variables were evaluated and compared using independent sample $t$ test. The mean \pm SD was calculated for each variable and P-value $<0.05$ was assumed as significant. To evaluate the effect of 1 unit increase in each quantitative variable on the odds of the outcome, linear and logistic regression was applied.

The quantitative parameter of interest (TSH level) was categorized in quartiles. Also, Pearson correlation coefficient was applied to assess the relationship between quantitative variables. 


\section{Results:}

Basic and demographic features of all 82 patients are depicted in Table 1.

Patients with 3 or more criteria of MetS were classified in Group1 (MetS) and patients with 0,1 or 2 criteria in Group2 (non-MetS). Mean \pm SD age of the patients was $42.10 \pm 10.19$ years (maximum 70 and minimum 23 years old). Fifty-five patients were male, with the mean \pm SD age of $39.8 \pm 9.68$ years. Female patients were older than the male ones (46.7 vs. 39.8, P-value=0.004). TG, BP, WC, BMI, hs$\mathrm{CRP}$, and age were significantly higher in Group 1. Although patients with MetS had greater TSH level, it was not statistically significant between the groups (P-value $=0.636)$. Two patients had one, 25 patients had two, 38 patients had three, 19 patients had four and 8 patients had 5 MetS criteria. MetS criteria are shown and compared based on gender subgroups in Table 2. All the female patients with MetS had the WC $>102 \mathrm{~cm}$.

Table 1. Basic and Demographic Features, MetS, and Non-MetS in the Patients $(n=82)$

\begin{tabular}{|c|c|c|c|}
\hline & MetS $(n=55)$ n (\%) & Non-MetS $(n=27)$ n (\%) & P-value \\
\hline Female & $22(40 \%)$ & $5(18.5 \%)$ & \multirow{2}{*}{0.052} \\
\hline Male & $33(60 \%)$ & $22(81.5 \%)$ & \\
\hline Age (year) mean \pm SD & $43.69 \pm 10.27$ & $38.85 \pm 9.43$ & $0.043 *$ \\
\hline $\mathrm{WC}^{\mathrm{a}}(\mathrm{cm})$ mean $\pm \mathrm{SD}$ & $104.4 \pm 7.5$ & $100.2 \pm 9.4$ & $0.03^{*}$ \\
\hline $\mathrm{TG}^{\mathrm{b}}(\mathrm{mg} / \mathrm{dL})$ mean $\pm \mathrm{SD}$ & $235.6 \pm 173.5$ & $159.6 \pm 65.9$ & $0.006^{*}$ \\
\hline $\mathrm{HDL}^{\mathrm{c}}(\mathrm{mg} / \mathrm{dL})$ mean $\pm \mathrm{SD}$ & $34.5 \pm 10.3$ & $38.6 \pm 12.5$ & 0.125 \\
\hline FBS $^{d}(\mathrm{mg} / \mathrm{dL})$ mean \pm SD & $106 \pm 35.7$ & $92.2 \pm 24.2$ & 0.075 \\
\hline HTN $^{\mathrm{e}}$ positive patients (\%) & $31(56.4 \%)$ & $7(26 \%)$ & $0.009 *$ \\
\hline $\operatorname{BMI}^{\mathrm{f}}\left(\mathrm{kg} / \mathrm{m}^{2}\right)$ mean $\pm \mathrm{SD}$ & $31.9 \pm 3.7$ & $29.5 \pm 3.8$ & $0.007 *$ \\
\hline TSH $^{\mathrm{g}}(\mathrm{UI} / \mathrm{mL})$ mean \pm SD & $2.9 \pm 0.86$ & $2.8 \pm 1.2$ & 0.636 \\
\hline $\mathrm{T3}^{\text {h }}(\mathrm{ng} / \mathrm{dL})$ mean $\pm \mathrm{SD}$ & $122.6 \pm 16.7$ & $123.8 \pm 20.25$ & 0.77 \\
\hline 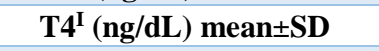 & $7.3 \pm 1.7$ & $7.6 \pm 1.2$ & 0.49 \\
\hline hs-CRPj $(\mathrm{mg} / \mathrm{dL})$ mean \pm SD & $25.7 \pm 12.6$ & $20.2 \pm 9.8$ & $0.049 *$ \\
\hline
\end{tabular}

${ }^{\mathrm{a}}$ Waist circumference; ${ }^{\mathrm{b}}$ Triglyceride; ${ }^{\mathrm{c}}$ High density lipoprotein; ${ }^{\mathrm{d}}$ Fasting blood sugar; ${ }^{\mathrm{e}}$ Hypertension; ${ }^{\mathrm{f}}$ Body mass index; ${ }^{\mathrm{g}}$ Thyroid stimulating hormone; ${ }^{\mathrm{h}}$ Triiodothyronine; 'Thyroxine;

${ }^{\mathrm{j}}$ high-sensitivity C-reactive protein; * Significant P-value

Table 2. MetS Criteria in Group $1(n=55)$

\begin{tabular}{|c|c|c|c|}
\hline & Female $(n=22) n(\%)$ & Male $(n=33) n(\%)$ & P-value \\
\hline $\mathrm{SBP}>130$ or $\mathrm{DBP}>85^{*}(\mathrm{Hg} \mathrm{mm})$ & $10(45.5 \%)$ & $21(63.6 \%)$ & 0.183 \\
\hline HDL $<50$ in females / HDL $<40$ in males $*(\mathrm{mg} / \mathrm{dL})$ & $18(81.8 \%)$ & $30(91 \%)$ & 0.322 \\
\hline TG $>150 \mathrm{mg} / \mathrm{dL} *$ & $18(81.8 \%)$ & $22(66.7 \%)$ & 0.216 \\
\hline $\mathrm{WC}>88$ in females $\mid \mathrm{WC}>102$ in males $*(\mathrm{~cm})$ & $22(100 \%)$ & $21(63.64 \%)$ & $0.001 * *$ \\
\hline FBS $>100 *(\mathrm{mg} / \mathrm{dL})$ & $18(81.8 \%)$ & $20(60.6 \%)$ & 0.095 \\
\hline
\end{tabular}

*or Under treatment, **Significant $\mathrm{p}$-value

SBP, systolic blood pressure; DBP, diastolic blood pressure; HDL, high density lipoprotein; TG, triglyceride; WC, waist circumference; FBS, Fasting blood sugar

The most prevalent metabolic criterion was low HDL. HTN was more likely to be a MetS criterion in male patients rather than the female ones (P-value $=0.018)$; however, no significant difference was observed between males and females regarding other MetS criteria. Univariate linear regression was applied to assess the relationship between TFT and the outcome of the interest. T4 and T3 had There was a reverse, but statistically insignificant, relationship between $\mathrm{T} 4$ and $\mathrm{T} 3$, and MetS (P- values $=0.31$ and 0.42 , respectively). To check the association between high TSH levels (in upper normal range), TSH was grouped in quartiles (Table 3 ).

The uppermost quartile was compared with other groups in terms of odds ratio in binary logistic regression. Euthyroid patients with TSH levels in the range 3.88-5 mIU/L, had 5.89 (95\% confidence interval $(\mathrm{CI})=1.02$ to 17.64$)$ times higher risk of developing MetS than other TSH ranges. The 3 TFT parameters were included in 
multivariate binary logistic regression, the TSH uppermost quartile was still significantly related to the outcome (OR=4.11, P-value=0.049); however, after adjustment for age, this relationship became insignificant $(\mathrm{OR}=2.97$, 95\% $\mathrm{CI}=0.51$ to 17.2). To appraise the association between TSH level and MetS criteria, univariate linear regression was applied. There was no significant relationship between TSH and lipid profile or WC in the current study $(\mathrm{P}$-value $=0.32,0.43,0.23$ and 0.54 for TG, TC, HDL and WC, respectively). Independent sample $t$ test was used to compare diastolic blood pressure (DBP) between groups 1 and 2. In MetS group, patients had significantly higher DBP than the ones in non-MetS group (86.02 vs. $80.48 \mathrm{mmHg}, \quad$ P-value $=0.031)$. Pearson correlation coefficient indicated insignificant relationship between hs-CRP and TSH level (0.005 , P-value $=0.98)$. The relationship between $2.5<\mathrm{TSH}<5 \mathrm{mIU} / \mathrm{L}$ and $\mathrm{HDL}<50 \mathrm{mg} / \mathrm{dL}$ was significant in the current study (Pearson Chisquare $n=2.3$, P-value $=0.049$ ).

Table 3. TSH levels in quartiles

\begin{tabular}{ccccc}
\hline TSH $(\mathbf{m I U} / \mathbf{L})$ & MetS $(\mathbf{n}=\mathbf{5 5})$ & Non-MetS $(\mathbf{n}=\mathbf{2 7})$ & Odds Ratio & P-value \\
\hline $\mathbf{0 . 5 - 1 . 6 2 5}$ & 10 & 4 & $1 *$ & - \\
\hline $\mathbf{1 . 6 2 6 - 2 . 7 5}$ & 19 & 10 & $1 *$ & - \\
\hline $\mathbf{2 . 7 6 - 3 . 8 7}$ & 13 & 10 & 5.89 & 0.024 \\
\hline $\mathbf{3 . 8 8 - 5}$ & 13 & 3 & 5. \\
\hline
\end{tabular}

*reference group in univariate binary logistic regression TSH, thyroid stimulating hormone; MetS, metabolic syndrome TSH normal range: $0.5-5 \mathrm{mIU} / \mathrm{L}$

\section{Discussion}

Bacterial Debates are almost about defining the upper normal limit of TSH. The answer is important because the leading cause of death in the world, cardiovascular disease, is more prevalent in overt hypothyroidism. However, the impression of subclinical hypothyroidism and TSH at upper normal limits on CVD is still disputable. Aging and metabolic syndrome predispose individuals to coronary artery disease. The current study tried to determine the net and adjusted effect of TSH levels on MetS and its 5 components in euthyroid patients with obesity.

In the current cross sectional study on euthyroid patients with obesity, a significant relationship was observed between TSH at upper normal limits and MetS. In a previous study in Taiwan (12), subclinical hypothyroidism was speculated as a risk factor for MetS and the level of TSH was significantly higher in MetS group than in nonMetS. In the current investigation, despite a previous study by Wang et al. (6), the relevancy between TSH and MetS criteria was called into question. Positive relationship between TSH level and TC was reported in a cross sectional study (13).In the current study statistical population, TSH
$>2.5 \mathrm{mIU} / \mathrm{L}$ was significantly related to low HDL levels $(<50 \mathrm{mg} / \mathrm{dL})$ in euthyroid patients with overweight or obesity. However, there was no significant relationship between TSH and other MetS criteria. TSH cut off value of $2.5 \mathrm{mIU} / \mathrm{L}$ was selected here, since more than $95 \%$ of normal people have TSH levels below that, and TSH values greater than $2.5 \mathrm{mIU} / \mathrm{L}$ are predictive of the progression to clinical hypothyroidism (14).

Subclinical hypothyroidism may be a marker of aging and hypertension (15). In the current study, the association between TSH uppermost quartile level and MetS was insignificant when adjusting for age. DBP in the patients with MetS was higher than non-Met $S$ group. In a previous study by Park et al. (5), TSH had positive relationship with DBP in euthyroid post-menopausal females; however, it was not significant in the current study on euthyroid patients with obesity.

Hypothyroidism may lead to obesity, but one should notice that the TSH levels are also higher in patients with obesity; whether within normal range or slightly higher than upper normal limits (16). The effect of leptin hormone released from adipose 
tissue on hypothalamus-pituitary axis may alter TSH secretion in patients with obesity (17).

Obesity affects both insulin resistance and thyroid hormone functioning; hence, the association between thyroid gland hormones and clinical features of insulin resistance (DLP, HTN, and diabetes) is challenging (12). Furthermore, diurnal variations of TSH level can cause selection bias; it is higher at night time (18). To deal with this issue blood samples were taken at about 8:00 AM after at least 10 hours of fasting. The association between hs-CRP and thyroid dysfunction is conflicting. A study by Hueston et al., showed no difference in hsCRP levels between euthyroid and hypothyroid patients (19). Subclinical hypothyroidism showed higher levels of hs-CRP in a study by Lee YK et al. (20). Pearson correlation between TSH levels in normal range and hs-CRP was negative, but insignificant in the current study.

Cross sectional studies cannot accurately indicate causality, but descriptive and comparative measures may be useful in such studies. Larger sample size of normal population and patients with overweight/obesity as well as euthyroid patients vs. the ones with hypothyroidism leads to a more precise conclusion.

\section{Conclusion:}

TSH in upper normal limits was significantly related to MetS. After adjusting for other thyroid hormones, this relationship remained significant; however, after adjusting for age, it became insignificant. The relationship between thyroid hormones and MetS may be confounded by other important CVD risk factors and the pure effect is still debating in euthyroid patients.

\section{Acknowledgement}

Authors would like to express their gratitude to the central laboratory staff of Imam Khomeini Hospital Complex for their effective cooperation and technical assistance.

Conflict of Interest The authors declare that there was no conflict of interest.

\section{References}

1. Grundy SM, Cleeman JI, Daniels SR, Donato KA, Eckel RH, Franklin BA, et al. Diagnosis and management of the metabolic syndrome: an American Heart Association/National Heart, Lung, and Blood Institute scientific statement. Curr Opin Cardiol. 2006;21(1):1-6.

2. Shantha GP, Kumar AA, Jeyachandran V, Rajamanickam D, Rajkumar K, Salim S, et al. Association between primary hypothyroidism and metabolic syndrome and the role of $\mathrm{C}$ reactive protein: a cross-sectional study from South India. Thyroid Res. 2009;2(1):2.

3. Vasan RS, Pencina MJ, Cobain M, Freiberg MS, D'Agostino RB. Estimated risks for developing obesity in the Framingham Heart Study. Ann Intern Med. 2005;143(7):473-80.

4. Power ML, Schulkin J. Sex differences in fat storage, fat metabolism, and the health risks from obesity: possible evolutionary origins. $\mathrm{Br} \mathbf{J}$ Nutr. 2008;99(05):931-40.

5. Park HT, Cho GJ, Ahn KH, Shin JH, Hong SC, Kim $\mathrm{T}$, et al. Thyroid stimulating hormone is associated with metabolic syndrome in euthyroid postmenopausal women. Maturitas. 2009;62(3):3015.

6. Wang C-Y, Chang T-C, Chen M-F. Associations between subclinical thyroid disease and metabolic syndrome. Endocr J. 2012;59(10):911-7.

7. Lai C-C, Tang S-H, Pei D, Wang C-Y, Chen Y$\mathrm{L}, \mathrm{Wu} \mathrm{C}-\mathrm{Z}$, et al. The prevalence of subclinical thyroid dysfunction and its association with metabolic syndrome in Taiwanese elderly. Int $\mathrm{J}$ Gerontol. 2011;5(1):25-9.

8. Michalopoulou G, Alevizaki M, Piperingos G, Mitsibounas D, Mantzos E, Adamopoulos P, et al. High serum cholesterol levels in persons with'highnormal'TSH levels: should one extend the definition of subclinical hypothyroidism? Eur J Endocrinol. 1998;138(2):141-5.

9. Åsvold BO, Vatten LJ, Nilsen TI, Bjøro T. The association between TSH within the reference range and serum lipid concentrations in a population-based study. The HUNT Study. Eur J Endocrinol. 2007;156(2):181-6.

10. McDermott MM, Liu K, Guralnik JM, Ferrucci L, Green D, Greenland P, et al. Functional decline in patients with and without peripheral arterial disease: predictive value of annual changes in levels of C-reactive protein and D-dimer. J Gerontol A Biol Sci Med Sci. 2006;61(4):374-9.

11. Taki K, Nishio K, Hamajima N, Niwa T. Metabolic syndrome defined by new criteria in Japanese is associated with increased liver enzymes 
and C-reactive protein. Nagoya J Med Sci. 2008;70(1):2.

12. Bastemir M, Akin F, Alkis E, Kaptanoglu B. Obesity is associated with increased serum TSH level, independent of thyroid function. Swiss Med Wkly. 2007;137(29/30):431.

13. Iqbal A, Jorde R, Figenschau Y. Serum lipid levels in relation to serum thyroid-stimulating hormone and the effect of thyroxine treatment on serum lipid levels in subjects with subclinical hypothyroidism: the Troms $\varnothing$ Study. J Intern Med. 2006;260(1):53-61.

14. Kim SS, Lee BJ, Lee JC, Kim SJ, Jeon YK, Kim MR, et al. Coexistence of Hashimoto's thyroiditis with papillary thyroid carcinoma: the influence of lymph node metastasis. Head \& neck. 2011;33(9):1272-7.

15. Sawin CT, Geller A, Wolf PA, Belanger AJ, Baker E, Bacharach P, et al. Low serum thyrotropin concentrations as a risk factor for atrial fibrillation in older persons. N Engl J Med. 1994;331(19):1249-52.

16. Reinehr T. Obesity and thyroid function. Mol Cell Endocrinol. 2010;316(2):165-71.
17. Mantzoros CS, Ozata M, Negrao AB, Suchard MA, Ziotopoulou M, Caglayan S, et al. Synchronicity of frequently sampled thyrotropin (TSH) and leptin concentrations in healthy adults and leptin-deficient subjects: evidence for possible partial TSH regulation by leptin in humans. J Clin Endocrinol Metab. 2001;86(7):3284-91.

18. 18.Atalay R, Ersoy R, Demirezer AB, Akın FE, Polat SB, Cakir B, et al. Day-night variations in thyroid stimulating hormone and its relation with clinical status and metabolic parameters in patients with cirrhosis of the liver. Endocrine. 2015;48(3):942-8.

19. Hueston WJ, King DE, Geesey ME. Serum biomarkers for cardiovascular inflammation in subclinical hypothyroidism. Clin Endocrinol (Oxf). 2005;63(5):582-7.

20. Lee YK, Kim JE, Oh HJ, Park KS, Kim SK, Park SW, et al. Serum TSH level in healthy Koreans and the association of TSH with serum lipid concentration and metabolic syndrome. Korean J Intern Med. 2011;26(4):432-9.

\section{How to Cite This Article:}

Nozarian Z, Abdollahi A, Mehrtash V, Nasiri Bonaki H. Upper Normal Limit of Thyroid-Stimulating Hormone and Metabolic Syndrome in Iranian Patients with Obesity. Iranian Journal of Pathology. 2017;12(1):88-93. 